\title{
Getting to the Warm Hand-Off: A Study of Home Visitor Referral Activities
}

\author{
Jessica Goldberg ${ }^{1}$ (D) $\cdot$ Jessica Greenstone Winestone ${ }^{1} \cdot$ Rebecca Fauth $^{1} \cdot$ Melissa Colón ${ }^{1} \cdot$ Maria Verónica Mingo $^{1}$
}

Published online: 2 June 2018

(C) The Author(s) 2018, Corrected publication August/2018

\begin{abstract}
Introduction Conducted as part of the Massachusetts MIECHV evaluation, this study examined the role of home visitors (HVs) in facilitating families' connections to early childhood systems of care. The aims of this study were to document the full range of $\mathrm{HV}$ behaviors related to service coordination.

Methods The study sample was 65 participant cases from five program sites, comprising two home visiting models (HFM and PAT). We coded and analyzed 11,096 home visiting records, focusing on identifying referrals, connections, disconnections, and supportive behaviors across 20 service areas. Qualitative pattern analyses were conducted on a subsample of records to identify unique pathways from referral to connection.

Results HVs discussed an average of 30 different programs with each participant, and overall, only $21 \%$ of referrals resulted in a service connection. This rate varied, with some (e.g., housing) requiring much more intensive HV support and yielding far fewer connections. HVs also worked to keep participants engaged once they were connected to a service, often discovering challenges in need of attention through monitoring activities.

Discussion Home visiting is often thought of as a key entry point into a system of care. Findings from this study confirm this premise, highlighting both the centrality of home visiting in helping families navigate local systems of care, and the insufficiency of these systems to meet family needs.
\end{abstract}

Keywords Home visiting $\cdot$ Service coordination $\cdot$ System of care $\cdot$ Referrals

\section{Significance}

To date, there have been no comprehensive evaluations of service coordination within the home visiting context, particularly regarding the pathways that lead from referral to connection. This study of referral-making and service coordination in the Massachusetts MIECHV home visiting program, which details home visitors' efforts to help participants navigate services in their local systems of care, begins to address this gap in the literature and point to directions for further research.

Jessica Goldberg

jessica.goldberg@tufts.edu

1 Tufts University, 574 Boston Ave., Medford, MA 02155, USA

\section{Introduction}

Authorized as part of the 2010 Affordable Care Act, the Maternal, Infant, and Early Childhood Home Visiting program (MIECHV) provides federal funds to states and tribal entities to support evidence-based home visiting services to families in at-risk communities. MIECHV has a stated focus on early childhood systems building (Patient Protection and Affordable Care Act 2010); this recognition that home visiting is not a panacea, but rather an essential component in a larger system of care (Daro 2009), acknowledges the challenges of providing services to populations with multiple needs, situated in insufficiently resourced communities. There has been increasing interest in understanding how home visiting programs connect families to services and strengthen local systems of care (Minkovitz et al. 2016; Roberts et al. 1996). While literature investigating home visiting impacts on child and family outcomes is plentiful, far less attention has been given to the processes and outcomes associated with referral-making in home visiting. Conducted 
as part of the implementation evaluation of the Massachusetts (MA) MIECHV program this study is a mixed-methods process investigation of home visitors' (HV) role in facilitating and maintaining families' connections to other services in the early childhood system of care.

\section{Background}

MA MIECHV delivers home visiting services via four models [Early Head Start (EHS), Healthy Families America (HFA), Healthy Families Massachusetts (HFM), and Parents as Teachers (PAT)], in 17 high-need communities across MA. MA MIECHV aims to help families across myriad domains (e.g., health, positive parenting, child development, economic self-sufficiency), either directly or by connecting families to resources and supports in their communities; the latter is the focus here.

Linkage to community resources has long been a stated component of home visiting programs' offerings (Duggan et al. 1999; Olds and Kitzman 1993; Roberts et al. 1996), and the 2010 MIECHV legislation, which includes coordination and referrals to needed services as one of its benchmark domains (Adirim and Supplee 2013), brought this aspect of home visiting into sharper focus. Despite this redoubled emphasis, little is known about whether and how home visiting programs are meeting this service coordination need. As an example, of the 20 home visiting models established as evidence-based (EBHV) by the U.S. Department of Health and Human Services (Avellar et al. 2017), only six considered linkages and referrals in their assessment of program outcomes (Anisfeld et al. 2004; Dodge et al. 2014; Jacobs et al. 2015; LeCroy and Krysik 2011; Love et al. 2002; Lowell et al. 2011; Olds et al. 1986; Silovsky et al. 2011).

These evaluations focused on two service coordination outcomes: whether a referral was made, and whether a connection to service occurred. Programs with a designated case manager/service coordinator on the home visiting team demonstrated success connecting families to community services (EHS, Love et al. 2002; Child First; Lowell et al. 2011), as did programs with a stated focus on service coordination as a key service offering (Family Connects, Dodge et al. 2014; SafeCare Augmented; Silovsky et al. 2011). Findings from evaluations of programs without an explicit focus on service coordination are less consistent; while HFA programs in Kentucky (Williams et al. 2017) and Oregon (Green et al. 2017) successfully connected families to community resources, for instance, other state HFAs (e.g., Hawaii, Massachusetts, Arizona) were found to have no effects on service linkage (Duggan et al. 2004; Jacobs et al. 2015; LeCroy and Krysik 2011).

Evaluations of early intervention (EI) programs (not considered EBHV) have examined service coordination in more depth, perhaps because EI is legislatively mandated to offer case management to participants (Peterson 1991). Qualitative investigations of EI parents' attitudes around referralmaking have found that these families expect and value HVs' help connecting them to services (Able-Boone et al. 1990; Allen 2007; Mahoney et al. 1990; Roberts et al. 1996). In one of the few studies focusing on service coordination in the context of a HV's workload, Roberts et al. (1996) found that HVs spent $40 \%$ of their time integrating services for families.

To our knowledge, there have been no evaluations that comprehensively explore how service coordination operates within home visiting programs, particularly regarding the pathways that lead from referral to connection. This study, which details HVs' efforts to help young mothers navigate services in their local systems of care, begins to address this gap in the literature. Our operationalization of referral-making was informed by the information and referral (I\&R) services field, which suggests that referrals are more than a one-time event, and emphasizes the importance of follow-up support activities as part of the referral-making processes (AIRS 2016; Gutiérrez 1992; Levinson 2002; Long 1973). The present study documented the full range of HV behaviors involved in service coordination, including behaviors intended to identify needs, connect participants to services, and maintain their engagement once connected.

\section{Methods}

For this mixed methods study, we employed qualitative methods to code the data and examine pathways from referrals to connections, and conducted quantitative analyses of referrals, HV support behaviors, and service connections.

\section{Data Source}

Our data source was participant case histories drawn from referral, secondary activity, and home visit records contained within home visiting programs' web-based management information system (MIS). HVs use this system to track background information about participants (e.g., demographics), service delivery (e.g., the content of home visits, referrals, and other services), goal setting and attainment, and child and mother assessments. Referral records included the description of the program to which the family is referred, and the referral outcome. Secondary activity records described any non-visit activities (e.g., dropping off diapers, contacts with other service providers) conducted by the HV with or for the participant. Home visiting records included HVs' narrative summaries of what was discussed with, or observed about, the participant across multiple service areas (e.g., 
housing, child care). We defined a "record" as a single note recorded by a HV in any of these three sources.

\section{Samples}

We used a stratified, weighted sample of 65 participant cases from five demographically diverse program sites comprising two home visiting models (HFM and PAT), randomly selecting cases from each site based on program capacity. The records used for this study covered a 4-year period (2012-2016), encompassing participants' entire duration in the program.

\section{Coding}

As a first step, a team of six coders reviewed all records for the 65 participants in the sample, retaining those containing any mention of community service-related activities. Next, coders organized these codeable records into "service discussions," or chronologically ordered records within a participant's case history related to that one specific program or service. For example, a discussion may start on one visit with the participant expressing a desire to attend college, and subsequent visits may include the HV and participant completing applications and making calls to admissions offices. The last record in which the college is mentioned by the HV would be considered the "end" of the discussion.

Finally, we coded each record in the discussions, using a multi-level scheme capturing all stages of HVs' facilitation of participants' linkages to community services, including pre-referral activities (e.g., suggesting a service), referrals (i.e., the initial action taken to link a participant to a service), referral follow-up activities (e.g., assistance completing applications), service connection, service disconnection, post-connection activities (e.g., satisfaction check-ins), and post-disconnection activities (e.g., attempts to re-engage). Codes also characterized the primary goal of each discussion [i.e., to connect a participant to a service ("linking mode"), or support an existing connection ("maintaining mode")]. We identified a hierarchy of HV behavior codes, based on the intensity of time and effort required from HVs in providing each type of support, including low-level support (checkins), moderate support (encouragement/suggestions/advic e; emotional support/cheerleading; information provision), and advanced support (instrumental support; interagency case review) (see Table 1). A detailed coding manual with definitions and examples guided coders. We achieved an interrater reliability rate of $85 \%$ based on $20 \%$ of the records.

\section{Analysis}

Overall sample statistics are based on data aggregated at the participant level, and statistics for each service area are

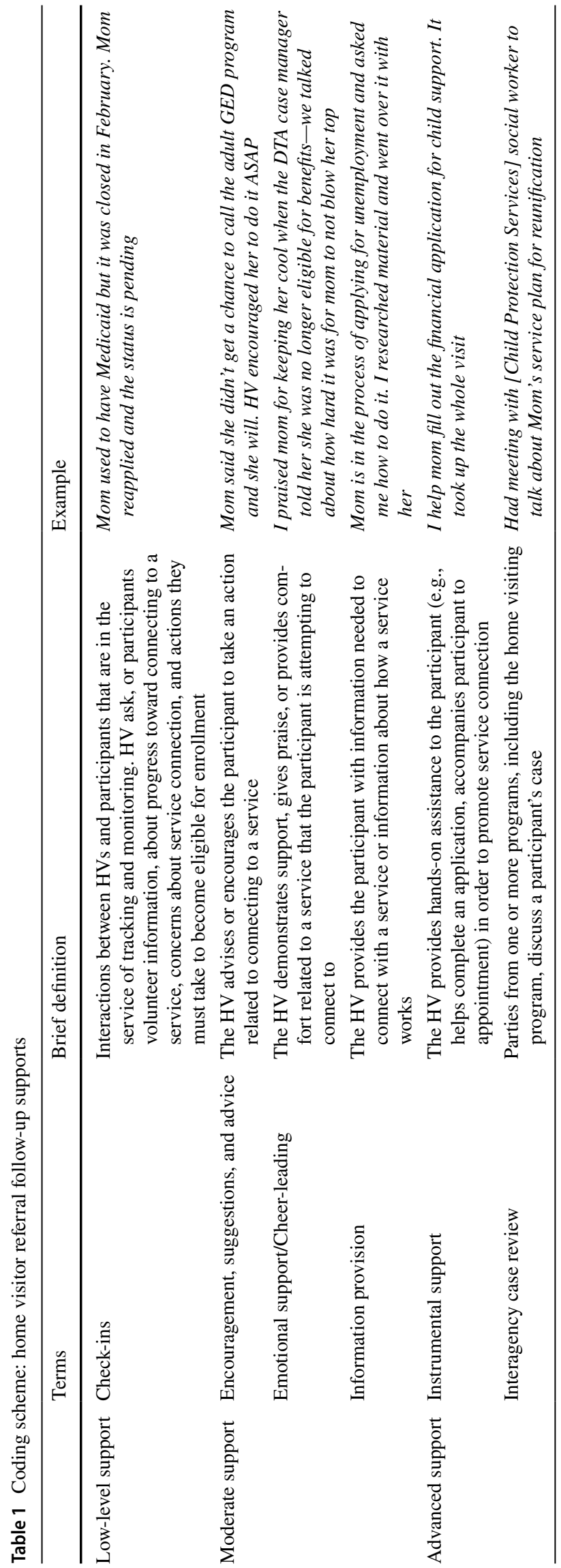


based on records nested within discussions. For the qualitative component, we used in-depth pattern analyses to create case studies for 20 participants, randomly selected from the larger sample. In this paper we focus largely on the content and frequency of HV behaviors that occurred after $a$ referral (rather than the full range of behaviors), and present two case studies that are particularly good illustrations of the nature of HV-participant interactions around service coordination.

\section{Consent and Approval}

Our research team is granted access to the MIS records through our ongoing evaluation contract with the home visiting program; our research group is named in the informed consent participants sign when enrolling in MA MIECHV. This research was approved by the Tufts University Institutional Review Board.

\section{Results}

In this section we report findings related to: the frequency with which HVs document service coordination activities, and the proportion of activities that are referrals; the distribution of referrals across service areas; the types of referral follow-up supports HVs offer; and the pathways from referral to service connection.

\section{Frequency of Discussions Related to Service Coordination Activities}

As seen in Table 2, there was a total of almost 55,000 records across the 65 participants. Of these, around one-fifth $(20.2 \%, n=11,096)$ contained mention of a community service; approximately 171 records per participant. These codeable records were organized into, on average, approximately 30 discussions about individual programs per participant, almost a third of which included a referral.

Table 2 Home visitor records pertaining to community services

\begin{tabular}{lrrrl}
\hline & $N$ & $M$ & SD & Range \\
\hline Total records & 54,959 & 845.52 & 496.48 & $41-1986$ \\
$\begin{array}{l}\text { Records containing mention of a } \\
\quad \text { community service }\end{array}$ & 11,096 & 170.70 & 119.24 & $1-557$ \\
$\begin{array}{l}\text { Service discussions } \\
\begin{array}{l}\text { Service discussions including a } \\
\text { referral }\end{array}\end{array}$ & 1947 & 29.95 & 13.99 & $1-65$ \\
\hline
\end{tabular}

\section{Distribution of Discussions and Referrals across Service Areas}

Of the 20 service areas we coded for, participants had discussions pertaining to 13 , on average (range 1-20) As shown in Fig. 1, most participants had at least one discussion related to medical (95\%), early education and care (94\%), economic/material assistance (92\%), housing (88\%), and food/nutrition services (88\%). Even the least common service areas (i.e., substance abuse, legal aid) were featured in at least one-fifth of the participants' records.

Participants generally had more than one discussion per service area. To understand where participants typically started with respect to each service area (i.e., linking vs. maintaining mode), we examined their first discussions. As shown in Fig. 1, the proportion of initial discussions that began in linking mode varied widely by service area. All of the participants who discussed a substance use program with their HVs, for instance, began these discussions in linking mode (i.e., they were not connected to the service, but likely needed to be), which was true for only a handful of participants who discussed health insurance (i.e., most participants were already connected to health insurance).

Figure 1 also shows the proportion of participants that had at least one discussion that included a referral. In some of the service areas, such as maternal health, behavioral health, domestic violence, and substance use, there was tight congruence between the proportions of participants who started a discussion in linking mode and those who went on to receive at least one referral, suggesting these are areas in which participants were specifically looking for referrals and HVs were well placed to provide them. On the other hand, there was little to no overlap between the two proportions in other service areas, such as child protection, and secondary and post-secondary education, areas in which participants either may not have wanted/needed referrals, or HVs were unable to provide them for some reason (see Fig. 1).

\section{HV Post-referral Follow-Up Behaviors}

For a more granular investigation of HV activities following referrals, we focused on the most prevalent and/ or salient service areas in our sample: behavioral health, early education and care, economic/material assistance, food/nutrition, housing, and maternal health. With regard to these service areas, the majority (68\%) of HVs' postreferral activities comprised low-level supports (checkins), and almost a third (32\%) were either moderate or advanced supports; this proportion was similar across service areas. 
Fig. 1 For each service area, proportions of participants who had at least one discussion, had a first discussion beginning in linking mode, and had at least one referral $(n=65)$

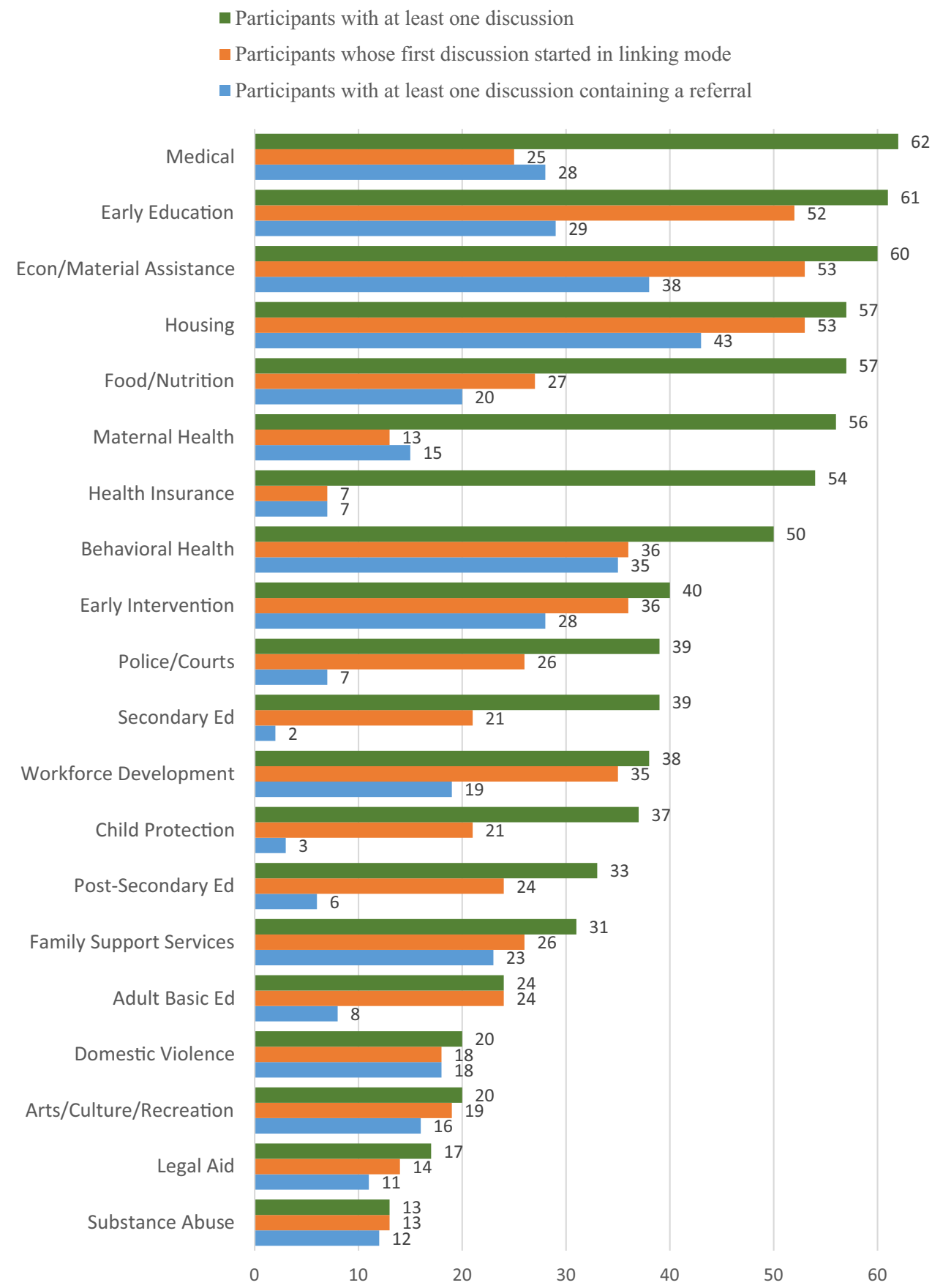

- Participants with at least one discussion

Participants whose first discussion started in linking mode

政$$
+2
$$ 
Table 3 Distribution of moderate/advanced supports following home visitor referral, by service area

\begin{tabular}{|c|c|c|c|c|c|c|c|c|c|c|c|}
\hline \multirow[t]{3}{*}{ Service area } & \multirow[t]{3}{*}{ Total } & \multicolumn{6}{|c|}{ Moderate supports } & \multicolumn{4}{|c|}{ Advanced supports } \\
\hline & & \multicolumn{2}{|c|}{$\begin{array}{l}\text { Encour- } \\
\text { agement, } \\
\text { suggestions, } \\
\text { advice }\end{array}$} & \multicolumn{2}{|c|}{$\begin{array}{l}\text { Emotional } \\
\text { support/ } \\
\text { cheerlead- } \\
\text { ing }\end{array}$} & \multicolumn{2}{|c|}{$\begin{array}{l}\text { Information } \\
\text { provision }\end{array}$} & \multicolumn{2}{|c|}{$\begin{array}{l}\text { Instrumental } \\
\text { support }\end{array}$} & \multicolumn{2}{|c|}{$\begin{array}{l}\text { Intera- } \\
\text { gency } \\
\text { case } \\
\text { review }\end{array}$} \\
\hline & & $n$ & $\%$ & $n$ & $\%$ & $n$ & $\%$ & $n$ & $\%$ & $n$ & $\%$ \\
\hline Behavioral health & 97 & 21 & 22 & 6 & 6 & 8 & 8 & 23 & 24 & 39 & 40 \\
\hline Early education & 62 & 16 & 26 & 3 & 5 & 12 & 19 & 23 & 37 & 8 & 13 \\
\hline Econ/material assistance & 31 & 6 & 19 & 0 & 0 & 2 & 6 & 23 & 74 & 0 & 0 \\
\hline Food/nutrition & 16 & 9 & 56 & 0 & 0 & 4 & 25 & 3 & 19 & 0 & 0 \\
\hline Housing & 77 & 11 & 14 & 1 & 1 & 21 & 27 & 42 & 55 & 2 & 3 \\
\hline Maternal health & 12 & 6 & $\mathbf{5 0}$ & 1 & 8 & 1 & 8 & 2 & 17 & 2 & 17 \\
\hline
\end{tabular}

Bold type indicates the most common type of moderate/advanced home visitor support following referrals in each service area
Table 4 Referrals and connections, by service area

\begin{tabular}{lcrl}
\hline Service area & Total referrals & $\begin{array}{l}\text { Connections to } \\
\text { service }\end{array}$ \\
\cline { 3 - 4 } & & $n$ & $\%$ of Referrals \\
\hline Behavioral health & 65 & 18 & 28 \\
Early education and care & 67 & 7 & 10 \\
Economic and material assis- & 75 & 20 & 27 \\
$\quad$ tance & 33 & 10 & 30 \\
Food and nutrition & 88 & 11 & 13 \\
Housing & 21 & 6 & 29 \\
Maternal health & 349 & 72 & 21 \\
Total & &
\end{tabular}

\section{HV Support Behaviors between Referrals and Connections}

Figure 2 shows the intensity of HV effort (moderate or advanced support) relative to the success in connecting for each of the six service areas. Referrals to maternal health and food/nutrition services required only moderate effort, and resulted in a relatively high number of connections. Referrals to behavioral health services and economic/material assistance required more intensive follow-up, but yielded similar rates of connection. Early education and housing also required more advanced effort, but yielded the fewest connections (10 and 13\%).

\section{In-Depth Exploration of Service Discussions}

Our primary interest for the in-depth analysis of 20 participants was to generate an understanding of the pathways from referral to connection. While a presentation of findings from this study component is beyond the scope of this paper, we present two of the qualitative case studies, illustrative of HV-participant interactions around service coordination, and highlighting the range and complexity of the HVs' roles vis a vis their clients. As background, the participant
Fig. 2 Distribution of moderate and advanced supports preceding connection to services, by service area

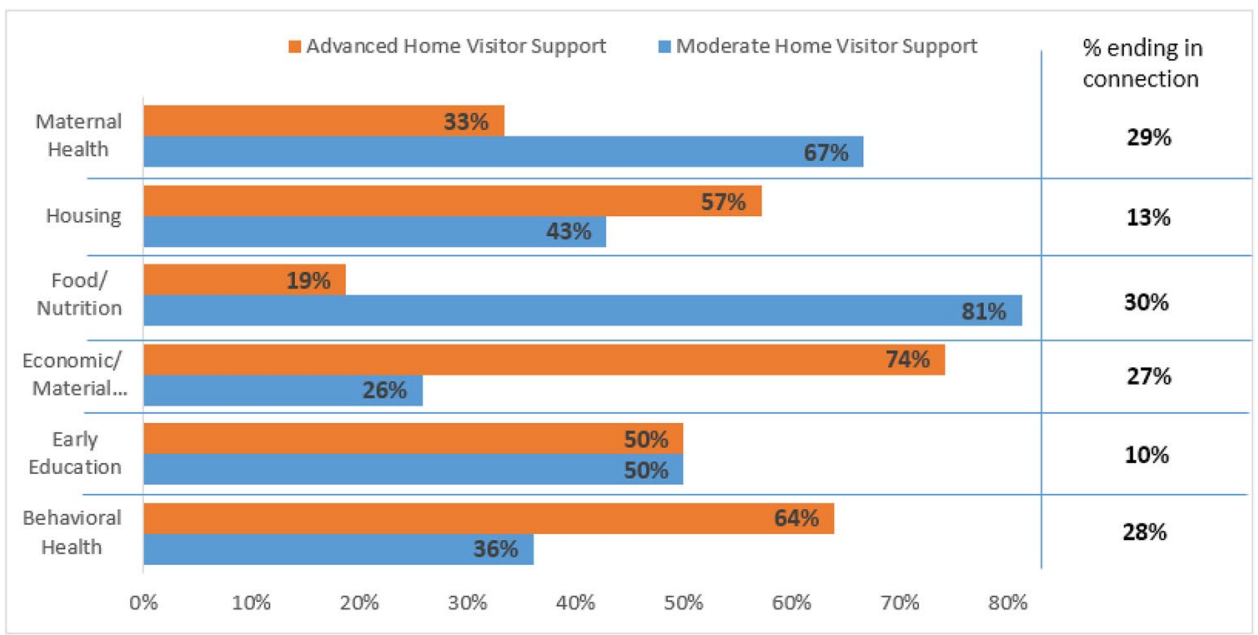


in the first example (Fig. 3) was enrolled in the program for 2.94 years, during which she received 64 home visits. She had a total of 61 service discussions with her HV, which included eight referrals, and eight connections, across four service areas. In this example the $\mathrm{HV}$ and participant talked about the service - a childcare voucher program - for more than 2 years before the participant made a connection. The HV provided instrumental support (e.g., contacting agencies

\begin{tabular}{|c|c|}
\hline Time & Summary of Home Visitor and Participant Interactions \\
\hline $\begin{array}{c}\text { Jul-Sep } \\
2012\end{array}$ & $\begin{array}{l}\text { Home visitor (HV) checked in with the mother (MOB) about child care, MOB said father of } \\
\text { the baby (FOB) was watching baby at the time, but when FOB got a job she would need } \\
\text { childcare. HV referred MOB (gave her a phone \# and explained how vouchers work) to a child } \\
\text { care resource center (CCR) where she could get a childcare voucher to use when the time came. } \\
\text { In the meantime, the HV was educating and coaching the mother on how to evaluate childcare } \\
\text { centers based on their features, care hours, and other factors. } \\
\text { After a couple weeks, MOB reported having trouble reaching anyone at CCR, so HV had her } \\
\text { sign a release so HV could call on her behalf. HV also reminded MOB that she would need a } \\
\text { written referral from the Department of Transitional Assistance (DTA) to bring to CCR. HV } \\
\text { encouraged MOB to keep calling CCR, to get the process started over the phone. MOB told HV } \\
\text { that she had given the information to DTA but still had not heard back from them, or CCR. } \\
\text { Both MOB and HV made multiple attempts over the next couple weeks to reach both } \\
\text { programs, with no success. HV suggested MOB make an appointment with CCR online. MOB did } \\
\text { this, but didn't like that the soonest appointment was a few weeks away, given that her need for } \\
\text { childcare had become more pressing, so at the next visit HV and MOB called together and made } \\
\text { a new appointment at CCR. } \\
\text { MOB missed her appointment at CCR [HV did not record reason]. } \\
\text { MOB did complete some necessary paperwork related to the referral from DTA and with her } \\
\text { school. MOB was not able to reach CCR to reschedule. After several attempts, HV reached } \\
\text { MOB's DTA worker to check in about MOB's paperwork, and also scheduled a new appointment } \\
\text { at CCR for MOB. }\end{array}$ \\
\hline $\begin{array}{l}\text { Oct-Dec } \\
2012\end{array}$ & $\begin{array}{l}\text { MOB reported that she no longer needed child care because FOB's mom would watch the } \\
\text { baby. [It is implied that MOB does not attend the second scheduled CCR appointment]. } \\
\text { MOB reported getting the referral from DTA and said that if she could still get the voucher } \\
\text { from CCR she would do it. HV told her to look on Mass.gov and search for providers where she } \\
\text { wanted baby to go (close to her school) so she could have a child care center in mind before } \\
\text { making an appointment at CCR. } \\
\text { MOB reported to HV that she found a child care center she liked and was ready to make an } \\
\text { appointment at CCR. } \\
\text { There was a 2-week delay when MOB misplaced the DTA referral, but then she relocated it } \\
\text { and was ready to make an appointment. HV called CCR and made an appointment for MOB. } \\
\text { But the week of the appointment, the mother told the home visitor that FOB would not be } \\
\text { attending school after all, and they did not need childcare. } \\
\text { MOB did not attend her third scheduled CCR appointment. }\end{array}$ \\
\hline $\begin{array}{l}\text { Jan } 2013- \\
\text { Jun } 2014\end{array}$ & $\begin{array}{l}\text { Over the next } 1.5 \text { years, } M O B \text { pieced together childcare with family members, and } H V \\
\text { periodically reminded } M O B \text { that getting on the voucher waitlist is a good idea even in the } \\
\text { absence of immediate childcare needs. }\end{array}$ \\
\hline $\begin{array}{c}\text { Jul-Sep } \\
\mathbf{2 0 1 4}\end{array}$ & $\begin{array}{l}\text { MOB finally received a childcare voucher (representing her successful connection to the } \\
\text { service) and was on a waitlist for a child care center she had visited and liked. MOB continued to } \\
\text { talk to HV about the child care centers she hoped to get into. }\end{array}$ \\
\hline $\begin{array}{l}\text { Oct-Dec } \\
2014\end{array}$ & $\begin{array}{l}\text { MOB told HV that when MOB called the center two months later to check in, they told her that } \\
\text { she had been mailed a letter saying a spot had opened up and that MOB had declined. MOB told } \\
H V \text { that did not happen, and HV told her to go down to CCR and talk to them about getting back } \\
\text { on the list. }\end{array}$ \\
\hline $\begin{array}{l}\text { Jan-Mar } \\
2015\end{array}$ & $\begin{array}{l}\text { MOB went to CCR and got back on the waiting list for a child care slot. She finally got a letter } \\
\text { offering her a spot, but when she contacted the center, the spot had already been filled. }\end{array}$ \\
\hline $\begin{array}{l}\text { Apr-Jun } \\
2015\end{array}$ & $\begin{array}{l}\text { MOB signed her baby up for Head Start but was told she had to wait until the baby turned } \\
\text { When baby turned } 3 \text { in June, MOB enrolled him in Head Start, to begin September. }\end{array}$ \\
\hline
\end{tabular}

Fig. 3 Service discussion example 1: childcare voucher 
and scheduling appointments on the participant's behalf,); encouragement to continue pursuing the service, persistent checking-in, which seemed to keep the goal of service connection on the participant's radar; and reminders to complete tasks necessary to advance her goal. The HV continued to work with the young woman on accessing child care through multiple setbacks, including missed appointments, administrative complications, and frequent mind-changing on the part of the participant.

The second example (Fig. 4) - a discussion about housing services that lasted more than a year-did not end in a connection to the desired service (subsidized apartment). This participant was enrolled in the home visiting program for 2.23 years, had 46 home visits, and had 48 service discussions. Of the thirteen referrals this participant received, across nine service areas, nine resulted in a connection. This discussion underscores the diversity of ways in which HVs support young mothers; in this example, the $\mathrm{HV}$ did not make any referrals, and did not play a connecting role, deferring instead to others to arrange the participant's housing placements. Rather, the HV focused on supporting the participant as she dealt with multiple housing transitions, providing instrumental and emotional support such as helping the young woman move her belongings, and offering advice to improve the quality of her living arrangement experiences. While the HV did not help the participant to secure stable, long-term housing during her tenure in the program, she remained a consistent support while this young

\begin{tabular}{|c|c|}
\hline Time & Summary of Home Visitor and Participant Interactions \\
\hline $\begin{array}{c}\text { Jul-Sept } \\
2013\end{array}$ & $\begin{array}{l}\text { When they began their discussion about housing, the mother had recently been relocated from a } \\
\text { homeless shelter to a Teen Living Program (TLP). Within a month of settling there she was asked } \\
\text { to leave. } \\
\text { HV drove her to the housing authority to drop off an application. MOB was told it would be at } \\
\text { least 3-4 months before she could get an apartment. }\end{array}$ \\
\hline $\begin{array}{c}\text { Oct-Dec } \\
2013\end{array}$ & $\begin{array}{l}\text { HV checked in with MOB to see if she had heard anything from the housing authority. MOB had } \\
\text { not, and HV told her to call them to check her status. MOB reported back that she found out she is } \\
\text { still on the waiting list. } \\
\text { HV and MOB had a couple discussions about MOB's mental health and how she is managing } \\
\text { living in the shelter. }\end{array}$ \\
\hline $\begin{array}{c}\text { Jan-Mar } \\
2014\end{array}$ & $\begin{array}{l}\text { HV periodically checked in with } M O B \text {, and reported that MOB was still on the waiting list for } \\
\text { housing and was "desperate" to get out of the shelter, feeling depressed about living there but } \\
\text { trying to keep a positive attitude. }\end{array}$ \\
\hline $\begin{array}{c}\text { Apr-Jun } \\
2014\end{array}$ & $\begin{array}{l}\text { MOB reported that her support workers from Child Protective Services (CPS) and the shelter } \\
\text { both told her it might help with housing to get a job. } \\
\text { MOB's shelter worker told her she was very close to getting an apartment. The following week, } \\
\text { MOB lost custody of her son to CPS and as a result had to move to a temporary shelter. } \\
\text { HV helped MOB move her belongings from her previous to the new shelter. } \\
\text { MOB was scared because she has heard stories about how violent it was there. HV gave MOB } \\
\text { recommendations about safety and conflict avoidance while residing there. } \\
\text { MOB texted HV to let her know she got a job at Subway and HV told her to let her shelter } \\
\text { worker and CPS case manager know. }\end{array}$ \\
\hline $\begin{array}{c}\text { Jul-Sep } \\
2014\end{array}$ & $\begin{array}{l}H V \text { talked to MOB's CPS worker and learned that MOB's unstable housing was a central } \\
\text { reason why she had not regained custody of her son. } \\
\text { MOB says she has not had a visit with her baby for more than a month. HV and MOB called } \\
C P S \text { worker together to check on the case and to schedule a CPS-supervised visit for HV and } \\
M O B \text { for the following week. } \\
\text { HV and MOB continued to have conversations about how MOB should deal with the violence at } \\
\text { the shelter. }\end{array}$ \\
\hline $\begin{array}{c}\text { Oct-Dec } \\
2014\end{array}$ & $\begin{array}{l}\text { HV informed CPS worker that she would need to discontinue services with MOB (the home } \\
\text { visiting program allows delivery of services to MOB without custody for a limited period of time). } \\
\text { MOB told HV that she found out she was at the top of the list to receive housing but would need } \\
\text { to have a reunification plan from CPS before the housing authority could proceed. } \\
\text { HV drove MOB to the CPS office. } \\
\text { [This is the last record; we do not know if the mother regained custody of her son, or if she } \\
\text { obtained housing after her discharge from the home visiting program.] }\end{array}$ \\
\hline
\end{tabular}

Fig. 4 Service discussion example 2: subsidized housing 
mother navigated what was clearly an extremely challenging time in her life.

\section{Discussion}

Results of this study suggest that the processes HVs engage in to connect participants to services are often complex, following a long and circuitous path with myriad steps involved (including those that involve trying to repair or resolve past challenges), multiple parties participating in the process, and fairly low success rates. Key conclusions are discussed below, followed by research limitations and implications for the home visiting field.

\section{Look Beyond Referrals to Understand HV Effort}

The few home visiting evaluations examining service coordination typically have focused on whether referrals were made (Anisfeld et al. 2004) and/or whether families were connected to services (Dodge et al. 2014; Duggan et al. 2004; Jacobs et al. 2015; Love et al. 2002; Olds et al. 1986; Silovsky et al. 2011; Williams et al. 2017). Our data, however, suggest that there are many HV behaviors beyond referrals that help participants gain access to, and navigate, local systems of care. Furthermore, as was illustrated in the housing case study, there is a wide range of outcomesother than a connection to a service-that may result from these activities, such as an increased ability to problem-solve or persist in the face of challenges. The home visiting field, and those to whom the field is accountable, would be wellserved by a broader understanding of how home visiting programs engage in service coordination; simply counting "referrals" sheds insufficient light on the role HVs play in helping participants navigate community systems.

\section{HV Effort Makes a Difference}

Moderate and advanced supports, such as instrumental support, encouragement, suggestions, and advice, interagency case review, and information provision were essential tools used by HVs to help participants realize connections to services. Through these supports, HVs helped participants navigate complex service requirements, encouraged tenacity in the face of failure and adversity, provided concrete supports that facilitated the application process, and reminded participants of important deadlines or appointments. Even in cases when HVs' support did not lead to successful service connection, it helped participants endure the challenges of applying for services, and learn to advocate for themselves. Qualitative findings from this study suggest the central role HVs can play in navigating structural barriers to service access (e.g., changing eligibility requirements, lack of transportation), but they also highlight the role HVs play in ameliorating some of the emotional barriers (e.g., participants' feelings of being disrespected, overwhelmed, defeated) families often experience during their encounters with the service system (Harris et al. 2016).

\section{The Majority of Referrals Do Not End in Service Connection}

On average, only about $20 \%$ of $\mathrm{HV}$ referrals resulted in a connection. This seems low; although it is important to note that we do not have an empirical frame of reference for this finding. The qualitative analyses illuminated the multiple complications that tended to arise during the pathway from referral to connection (or lack thereof). The amount of HV effort required to connect participants to services varied by service area; it took considerably more intensive HV effort to connect participants with housing and early education, for instance, than to maternal health and food/nutrition services. These findings map neatly onto the program and policy landscape of in which MA MIECHV was operating at the time. For instance, MA was ranked near the top of the nation in terms of coverage by health insurance (The Commonwealth Fund 2017), Women, Infants, and Children Food and Nutrition Service (WIC) (U.S. Department of Agriculture, January 2015), and Supplemental Nutrition Assistance Program (SNAP) (U.S. Department of Agriculture, February 2014), and near the bottom for housing (National Low Income Housing Coalition 2016) and child care affordability (Economic Policy Institute 2016). Findings from this study are further confirmation that linking participants to needed services is contingent on the quality, capacity, and strength of the service systems to which they are being referred.

\section{Limitations}

This study, a first attempt at understanding a complicated aspect of home visiting service delivery, had several limitations. First, due to our focus on service-related activities, we do not know what proportion of all $\mathrm{HV}$ activities is dedicated to service coordination. While it may be assumed that these activities take time away from other activities (e.g., parenting education) that home visiting programs believe to be important, this is not clear from the data. Future research should examine how service coordination fits into HVs' workloads, how service coordination is prioritized by home visiting programs compared to other goals, and the relative benefits to participants resulting from HVs' focus on service coordination versus other program goals. Second, there are limitations associated with using program records as the sole data source; HVs vary widely in their ability to consistently and thoroughly document services in the MIS, and without 
another primary data source with which to cross-reference the data, there was no way to verify their accuracy. Future studies should include data collected from participants as well, allowing for additional perspectives and better data triangulation. Third, the inclusion of only two program models in our study precluded analyses of differential approaches to service coordination by model; future research should examine model-specific variations in referral-related processes and outcomes. Finally, the outcome in this study was service connection, and how it was influenced by HV support activities and contextual factors related to service capacity and events in the participants' lives. More research is needed to understand whether HVs' efforts in this area lead to improvements in families' well-being.

\section{Implications and Conclusions}

Writing about home visiting more than two decades ago, Weiss noted that "the visitor intent on providing a holistic and family-focused service often uncovers family needs beyond those related narrowly to parenting practices or whatever the single primary focus of the program might be..." (Weiss 1993). With the advent of MIECHV, and its requirement that $\mathrm{HVs}$ regularly screen and refer participants in areas such as mental health, substance abuse, and domestic violence, HVs are increasingly likely to uncover needs for which there simply are not available community services-a reality that is challenging for both the provider and the family (Garg et al. 2016). Findings from this study highlight the lack of concrete resources for families in need, and the consequent difficulty experienced by HVs attempting to connect these families to services; housing in particular has emerged as a driving unmet need.

It is clear that the young women participating in home visiting programs are in profound need of access to a community system of care, and that HVs play a crucial role in helping these participants navigate this system. On the one hand, HVs are well-positioned to do this kind of work; on the other hand, service coordination is not the primary focus of home visiting; in fact, service coordination is currently seen as marginal to most home visiting services in MA, and is not part of the core training curriculum. And while we do not know if, say, time spent helping a participant complete a housing application detracts from a HV's ability to teach about developmental milestones, there is research suggesting that HVs could better perform the essential tasks of home visiting, and families would be better poised to benefit from the services, if families had adequate resources in place (Folger et al. 2016; Lowell et al. 2011; McBride and Peterson 1997; Weiss 1993). One solution that has been adopted with demonstrable success in several home visiting models (Ayton and Joss 2016; Folger et al. 2016; Love et al. 2002; Lowell et al. 2011) is to have a more robust service coordination strategy in place at the program level, perhaps in the form of a dedicated case manager/service coordinator.

Findings from this study confirm the inextricability with which HVs are embedded in community systems of care. They not only are providing essential direct services to young mothers, but also are working behind the scenes as conduits between participants and this system, facilitating access to services by informing participants about the existence and functions of the services, interpreting complicated policies, imparting skills that can be used to pursue needed services in the future, and providing emotional support throughout. Perhaps the true capacity of HVs to influence family outcomes is yet to be discovered as a result of the burden that service coordination represents. Perhaps, also, once the laborious efforts of these frontline staff are more fully understood, it will be easier to identify sustainable program and policy solutions to the challenges of service coordination within the home visiting context.

Acknowledgements This study was conducted with funding from the Children's Trust of Massachusetts (MA5014) and Massachusetts Department of Public Health (DPH), which is the state administrator of the Massachusetts Maternal, Infant, and Early Childhood Home Visiting Program (MA MIECHV). This project is/was supported by the Health Resources and Services Administration (HRSA) of the U.S. Department of Health and Human Services (HHS) under Grant Number X10MC29474 Maternal, Infant and Early Childhood Home Visiting Grant Program. All conclusions reached are those of the authors alone and do not necessarily represent the views of the funders.

Open Access This article is distributed under the terms of the Creative Commons Attribution 4.0 International License (http://creativeco mmons.org/licenses/by/4.0/), which permits unrestricted use, distribution, and reproduction in any medium, provided you give appropriate credit to the original author(s) and the source, provide a link to the Creative Commons license, and indicate if changes were made.

\section{References}

Able-Boone, H., Sandall, S. R., Loughry, A., \& Frederick, L. L. (1990). An informed, family-centered approach to public law 99-457: Parental views. Topics in Early Childhood Special Education, 10(1), 100-111.

Adirim, T., \& Supplee, L. (2013). Overview of the federal home visiting program. Pediatrics, 132(Supplement 2), S59-S64.

AIRS. (2016). AIRS standards and quality indicators for professional information and referral. Retrieved from https://www.airs.org/files /public/AIRS_Standards_8_0.pdf.

Allen, S. F. (2007). Parents' perceptions of intervention practices in home visiting programs. Infants \& Young Children, 20(3), 266-281.

Anisfeld, E., Sandy, J., \& Guterman, N. B. (2004). Best beginnings: A randomized controlled trial of a paraprofessional home visiting program: Technical report. Report to the Smith Richardson Foundation and New York State Office of Children and Family Services. New York: Columbia University School of Social Work. Avellar, S., Paulsell, D., Sama-Miller, E., Del Grosso, P., Akers, L., \& Kleinman, R. (2017). Home visiting evidence of effectiveness 
review: Executive summary. Washington, DC: Office of Planning, Research and Evaluation, Administration for Children and Families, U.S. Department of Health and Human Services.

Ayton, D., \& Joss, N. (2016). Empowering vulnerable parents through a family mentoring program. Australian Journal of Primary Health, 22(4), 320-326.

Daro, D. (2009). Embedding home visitation programs within a system of early childhood services. Chapin Hall Issue Brief. Chicago, IL: Chapin Hall at the University of Chicago.

Dodge, K. A., Goodman, W. B., Murphy, R. A., O’Donnell, K., Sato, J., \& Guptill, S. (2014). Implementation and randomized controlled trial evaluation of universal postnatal nurse home visiting. American Journal of Public Health, 104(S1), S136-S143.

Duggan, A., Fuddy, L., Burrell, L., Higman, S. M., McFarlane, E., Windham, A., \& Sia, C. (2004). Randomized trial of a statewide home visiting program to prevent child abuse: Impact in reducing parental risk factors. Child Abuse \& Neglect, 28(6), 623-643.

Duggan, A., McFarlane, E. C., Windham, A. M., Rohde, C. A., Salkever, D. S., Fuddy, L., et al. (1999). Evaluation of Hawaii's Healthy Start program. The Future of Children, 9(1), 66-90.

Economic Policy Institute. (2016). The cost of child care in Massachusetts. Retrieved from http://www.epi.org/child-care-costs-inthe-united-states/.

Folger, A. T., Brentley, A. L., Goyal, N. K., Hall, E. S., Sa, T., Peugh, J. L., et al. (2016). Evaluation of a community-based approach to strengthen retention in early childhood home visiting. Prevention Science, 17(1), 52-61.

Garg, A., Boynton-Jarrett, R., \& Dworkin, P. H. (2016). Avoiding the unintended consequences of screening for social determinants of health. JAMA, 316(8), 813-814.

Green, B. L., Sanders, M. B., \& Tarte, J. (2017). Using administrative data to evaluate the effectiveness of the Healthy Families Oregon home visiting program: 2-year impacts on child maltreatment \& service utilization. Children and Youth Services Review, 75, 77-86.

Gutiérrez, L. (1992). Information and referral services: The promise of empowerment. Information and Referral, 13, 1-18.

Harris, J. N., Ruedinger, E., \& Johnson, A. Z. (2016). Connecteen families: Improving teen family care coordination in Hennepin County. Journal of Adolescent Health, 58(2), S20.

Jacobs, F., Easterbrooks, M. A., Goldberg, J., Mistry, J., Bumgarner, E., Raskin, M., et al. (2015). Improving adolescent parenting: Results from a randomized controlled trial of a home visiting program for young families. American Journal of Public Health, 106, 342-349.

LeCroy, C. W., \& Krysik, J. (2011). Randomized trial of the Healthy Families Arizona home visiting program. Children and Youth Services Review, 33(10), 1761-1766.

Levinson, R. W. (2002). New routes to human services: Information and referral. New York: Springer.

Long, N. (1973). Information and referral services: A short history and some recommendations. Social Service Review, 47(1), 49-62.

Love, J. M., Kisker, E., Ross, C., Schochet, P. Z., Brooks-Gunn, J., Paulsell, D., et al. (2002). Making a difference in the lives of infants and toddlers and their families: The impacts of Early Head Start. Volumes i-iii: Final technical report [and] appendixes [and] local contibutions to understanding the program and their impacts. Washington, DC: U.S. Department of Health and Human Services, Head Start Bureau.

Lowell, D. I., Carter, A. S., Godoy, L., Paulicin, B., \& Briggs-Gowan, M. J. (2011). A randomized controlled trial of child first: A comprehensive home-based intervention translating research into early childhood practice. Child Development, 82, 193-208.

Mahoney, G., O'Sullivan, P., \& Dennebaum, J. (1990). A national study of mothers' perceptions of family-focused early intervention. Journal of Early Intervention, 14(2), 133-146.

McBride, S. L., \& Peterson, C. (1997). Home-based early intervention with families of children with disabilities: Who is doing what? Topics in Early Childhood Special Education, 17(2), 209-233.

Minkovitz, C. S., O’Neill, K. M., \& Duggan, A. K. (2016). Home visiting: A service strategy to reduce poverty and mitigate its consequences. Academic Pediatrics, 16(3), S105-S111.

National Low Income Housing Coalition. (2016) Out of reach: No refuge for low income renters. Retrieved from http://nlihc.org/ sites/default/files/oor/OOR_2016.pdf.

Olds, D. L., Henderson, C. R., Tatelbaum, R., \& Chamberlin, R. (1986). Improving the delivery of prenatal care and outcomes of pregnancy: A randomized trial of nurse home visitation. Pediatrics, $77(1), 16-28$.

Olds, D. L., \& Kitzman, H. (1993). Review of research on home visiting for pregnant women and parents of young children. The Future of Children, 3(3), 53-92.

Patient Protection and Affordable Care Act, Pub. L. No. 111-148, $\$ 2951,124$ Stat 334-343 (2010)

Peterson, N. L. (1991). Interagency collaboration under Part H: The key to comprehensive, multidisciplinary, coordinated infant/toddler intervention services. Journal of Early Intervention, 15(1), 89-105.

Roberts, R. N., Akers, A. L., \& Behl, D. D. (1996). Family-level service coordination within home visiting programs. Topics in Early Childhood Special Education, 16(3), 279-301.

Silovsky, J. F., Bard, D., Chaffin, M., Hecht, D., Burris, L., Owora, A., et al. (2011). Prevention of child maltreatment in high-risk rural families: A randomized clinical trial with child welfare outcomes. Children and Youth Services Review, 33(8), 1435-1444.

The Commonwealth Fund. (2017). Aiming higher: Results from the Commonwealth Fund scorecard on state health system performance. Retrieved from http://www.commonwealthfund.org/inter actives $/ 2017 / \mathrm{mar} / \mathrm{state}$-scorecard/.

U.S. Department of Agriculture. (2014). Calculating the Supplemental Nutrition Assistance Program (SNAP) program access index: A step-by-step guide for 2012.

U.S. Department of Agriculture. (2015). Special Supplemental Nutrition Program for Women, Infants, and Children (WIC) eligibles and coverage-2012: National and state-level estimates summary.

Weiss, H. B. (1993). Home visits: Necessary but not sufficient. The Future of Children, 3(3), 113-128.

Williams, C. M., Cprek, S., Asaolu, I., English, B., Jewell, T., Smith, K., \& Robl, J. (2017). Kentucky Health Access Nurturing Development Services home visiting program improves maternal and child health. Maternal and Child Health Journal, 21(5), $1166-1174$. 